\title{
CONSTRUCTAL DESIGN OF A CAVITY COOLED BY CONVECTION
}

\author{
L.A.O. ROCHA ${ }^{1}$, G. LORENZINI ${ }^{2}$, C. BISERNI ${ }^{3} \&$ Y. CHO ${ }^{1}$ \\ ${ }^{1}$ Federal University of Rio Grande, School of Engineering, Brazil. \\ ${ }^{2}$ Department of Agricultural Economics and Engineering, Alma Mater Studiorum-University of Bologna, Italy. \\ ${ }^{3}$ Dipartimento di Ingegneria Energetica, Nucleare e del Controllo Ambientale Università degli Studi di Bologna, Italy.
}

\begin{abstract}
This paper applies constructal design to optimize the geometry of a C-shaped cavity that penetrates into a solid conducting wall. The objective is to minimize the global thermal resistance between the solid and the cavity. There is uniform heat generation on the solid wall. The total volume and the cavity volume are fixed, but the geometric lengths of the C-shaped cavity can vary. The cavity is cooled by convection heat transfer. The results indicate that the shape of C-cavity is optimal when it penetrates the conducting wall almost completely for the external ratio of the solid wall smaller than 2 . For external ratio larger than 2 the optimal cavity ratio is the one that presents the largest cavity aspect ratio $\mathrm{H}_{0} / \mathrm{L}_{0}$. The results also show that the cavities with small or large external ratios $\mathrm{H} / \mathrm{L}$ are the ones that present better performance.

Keywords: cavities, constructal design, enhanced heat transfer, fins.
\end{abstract}

\section{INTRODUCTION}

This paper reports numerically the optimization of the global performance of a C-shaped cavity that intrudes into a solid conducting wall. The optimization is conducted by applying constructal design. According to this method 'the flow geometry is malleable and it is deduced from a principle of global performance maximization subjected to global constraints' [1,2]. This method is based on constructal theory: 'the view that flow configuration (geometry, design) can be reasoned on the basis of a principle of configuration, generation and evolution in time toward greater global flow access in systems that are free to morph' [3].

The many applications of constructal theory to generate configuration in nature, and engineering has been reviewed recently [4]. This reference shows how natural configuration - river basins, turbulence, animal design, crack in solids, earth climate, etc. - can be predicted by principle. The same principle can be applied in the engineering realm: packing of electronics, fuel cells, tree networks for transport of people, goods and information, etc.

The heat transfer field has dedicated great attention to the study of fins arrays $[5,6]$. Another class of configurations are the open cavities. These are the regions formed between adjacent fins, and they may represent essential promoters of nucleate boiling: see, for example, the Vapotron effect [7-9] that occurs as a consequence of the thermal interaction between a non-isothermal finned surface and a fluid locally subjected to a transient change of phase. The significance of fins and cavities are recognized by the application of constructal method in the pursuit of best shapes of assembly of fins $[10,11]$ and cavities [12-14].

In this paper we apply constructal design to optimize the geometry of the C-shaped cavity. According to constructal design, the cavity shape is free to change subject to volume constraints in the pursuit of maximal global performance. The global performance indicator is the global thermal resistance between the volume of the entire system (cavity and solid) and the surroundings. For simplicity and clarity, we consider two-dimensional bodies: the solid wall and the C-shaped intrusion with variable geometric lengths. 


\section{MODEL}

Consider the conducting body shown in Fig. 1. The configuration is two-dimensional, with the third dimension (W) sufficiently long in comparison with the height $\mathrm{H}$ and the length $\mathrm{L}$ of the volume occupied by the body. There is a C-shaped cavity intruded in the body. The solid is isotropic with the constant thermal conductivity $\mathrm{k}$. It generates heat uniformly at the volumetric rate $\mathrm{q}^{\prime \prime}\left(\mathrm{W} / \mathrm{m}^{3}\right)$. The outer surfaces of the heat generating body are perfectly insulated. The generated heat current (q"'A) is removed by convection heat transfer through the cavity walls. The heat transfer coefficient $h$ is uniform over all the exposed surfaces, as well as the environment temperature $\mathrm{T}_{\infty}$.

The objective of the analysis is to determine the optimal geometry $\left(\mathrm{H}_{0} / \mathrm{L}_{0}, \mathrm{H} / \mathrm{L}\right)$ that is characterized by the minimum global thermal resistance $\left(\mathrm{T}_{\max }-\mathrm{T}_{\infty}\right) /(\mathrm{q} " \mathrm{~A})$. According to constructal design [3], this optimization can be subjected to two constraints, namely, the total area,

$$
A=H L,
$$

and the cavity area,

$$
\mathrm{A}_{0}=\mathrm{H}_{0} \mathrm{~L}_{0} .
$$

This can be expressed as the cavity fraction

$$
\phi_{0}=\mathrm{A}_{0} / \mathrm{A} .
$$

The analysis that delivers the global thermal resistance as a function of the geometry consists of solving numerically the heat conduction equation along the solid region,

$$
\frac{\partial^{2} \theta}{\partial \tilde{x}^{2}}+\frac{\partial^{2} \theta}{\partial \tilde{y}^{2}}+1=0
$$

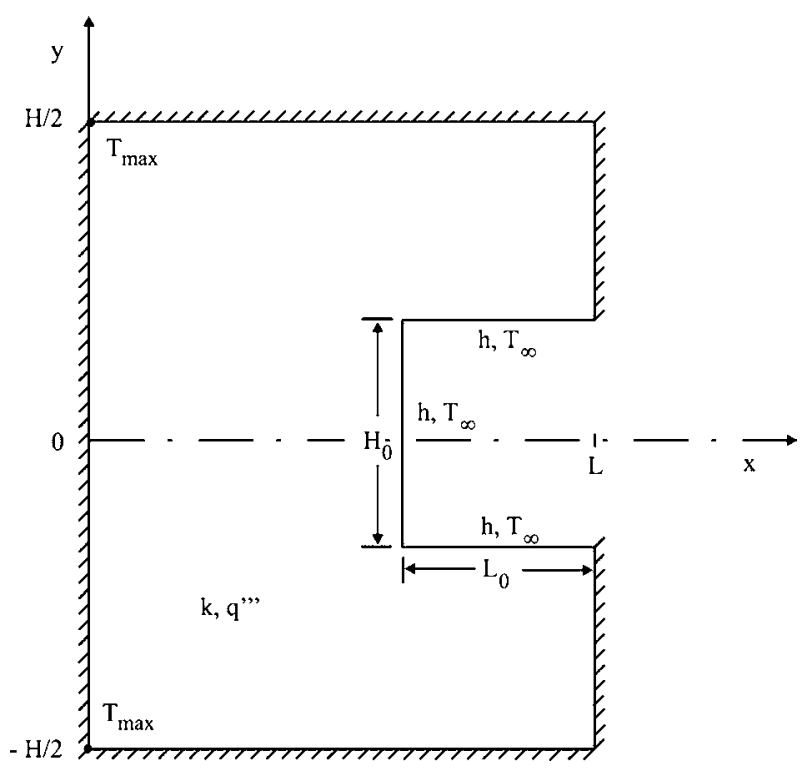

Figure 1: C-shaped cavity. 
where the dimensionless variables are

$$
\theta=\frac{\mathrm{T}-\mathrm{T}_{\infty}}{\mathrm{q} " \mathrm{~A} / \mathrm{k}}
$$

and

$$
\tilde{\mathbf{x}}, \tilde{y}, \tilde{\mathrm{H}}_{0}, \tilde{\mathrm{L}}{ }_{0}, \tilde{\mathrm{H}}, \tilde{\mathrm{L}}=\left(\mathrm{x}, \mathrm{y}, \mathrm{H}_{0}, \mathrm{~L}_{0}, \mathrm{H}, \mathrm{L}\right) / \mathrm{A}^{1 / 2} \text {. }
$$

The outer surfaces are insulated and their boundary conditions are

$$
\begin{gathered}
\frac{\partial \theta}{\partial \tilde{x}}=0 \quad \text { at } \tilde{x}=0 \text { and }-\frac{H}{2} \leq \tilde{y} \leq \frac{H}{2}, \\
\frac{\partial \theta}{\partial \tilde{x}}=0 \quad \text { at } \tilde{x}=L \text { and }-\frac{H}{2} \leq \tilde{y} \leq-\frac{H_{0}}{2} \text { or } \frac{H_{0}}{2} \leq \tilde{y} \leq \frac{H}{2}, \\
\frac{\partial \theta}{\partial \tilde{y}}=0 \text { at } \tilde{y}=-\frac{\tilde{H}}{2} \text { or } \tilde{y}=\frac{\tilde{H}}{2} \text { and } 0 \leq \tilde{x} \leq \tilde{L} .
\end{gathered}
$$

The boundary conditions on the cavity surfaces come from balancing the conduction and convection heat transfer, and their dimensionless resulting values are given by

$$
\begin{gathered}
-\frac{\partial \theta}{\partial \tilde{x}}=\lambda \theta \quad \text { at } \tilde{\mathrm{x}}=\left(\tilde{\mathrm{L}}-\tilde{\mathrm{L}}_{0}\right) \text { and }-\frac{\tilde{\mathrm{H}}_{0}}{2} \leq \tilde{\mathrm{y}} \leq \frac{\tilde{\mathrm{H}}_{0}}{2}, \\
-\frac{\partial \theta}{\partial \tilde{\mathrm{y}}}=\lambda \theta \quad \text { at } \tilde{\mathrm{y}}=-\frac{\tilde{\mathrm{H}}_{0}}{2} \text { or } \tilde{\mathrm{y}}=\frac{\tilde{\mathrm{H}}_{0}}{2} \text { and }\left(\tilde{\mathrm{L}}-\tilde{\mathrm{L}}_{0}\right)<\tilde{\mathrm{x}}<\tilde{\mathrm{L}},
\end{gathered}
$$

where $\lambda$ is defined as

$$
\lambda=\frac{\mathrm{hA}^{1 / 2}}{\mathrm{k}} .
$$

The dimensionless form of eqns (1) and (3) are

$$
1=\tilde{\mathrm{H}} \tilde{\mathrm{L}} \text { and } \phi_{0}=\tilde{\mathrm{H}}_{0} \tilde{\mathrm{L}}_{0} \text {. }
$$

The maximal excess temperature, $\theta_{\max }$, is also the dimensionless global thermal resistance between the volume of the entire system (cavity and solid) and the surroundings

$$
\theta_{\max }=\frac{\mathrm{T}_{\max }-\mathrm{T}_{\infty}}{\mathrm{q} ' \mathrm{~A} / \mathrm{k}}
$$




\section{NUMERICAL METHOD}

The function defined by eqn (14) can be determined numerically, by solving eqn (4) for the temperature field in every assumed configuration $\left(\mathrm{H} / \mathrm{L}, \mathrm{H}_{0} / \mathrm{L}_{0}\right)$, and calculating $\theta_{\max }$ to see whether $\theta_{\max }$ can be minimized by varying the configuration. In this sense, eqn (4) was solved using a finite elements code, based on triangular elements, developed in MATLAB environment, precisely the PDE (partial-differential-equations) toolbox [15]. The grid was non-uniform in both $\tilde{x}$ and $\tilde{y}$, and varied from one geometry to the next. The appropriate mesh size was determined by successive refinements, increasing the number of elements four times from the current mesh size to the next mesh size, until the criterion $I\left(\theta_{\max }^{\mathrm{j}}-\theta_{\max }^{\mathrm{j}+1}\right) \mid / \theta_{\max }^{\mathrm{j}}<1 \times 10^{-4}$ was satisfied. Here $\theta_{\max }^{\mathrm{j}}$ represents the maximum temperature calculated using the current mesh size, and $\theta_{\max }^{\mathrm{j}}$ corresponds to the maximum temperature using the next mesh, where the number of elements was increased by four times. Table 1 gives an example of how grid independence was achieved. The following results were performed by using a range between 2,000 and 10,000 triangular elements. The validation of the numerical method has been tested in former works [12-14] and will not be shown.

\section{CONSTRUCTAL GEOMETRY}

The numerical work consisted of determining the temperature field in a large number of configurations of the type shown in Fig. 1. Figure 2 shows that there is an optimal cavity ratio $\left(\mathrm{H}_{0} / \mathrm{L}_{0}\right)_{\text {opt }}$ that

Table 1: Numerical tests showing the achievement of grid independence $\left(\phi_{0}=0.1, \lambda=1, \mathrm{H} / \mathrm{L}=1\right.$, $\left.\mathrm{H}_{0} / \mathrm{L}_{0}=0.15, \mathrm{H} / \mathrm{L}=1\right)$.

\begin{tabular}{lcc}
\hline Number of elements & $\theta_{\max }^{\mathrm{j}}$ & $\mathrm{I}\left(\theta_{\max }^{\mathrm{j}}-\theta_{\max }^{\mathrm{j}+1}\right) / \theta_{\max }^{\mathrm{j}}$ \\
\hline 161 & 0.642868 & $5.693 \times 10^{-4}$ \\
644 & 0.643239 & $1.305 \times 10^{-4}$ \\
2,576 & 0.643318 & $2.487 \times 10^{-5}$ \\
10,304 & 0.643334 & \\
\hline
\end{tabular}

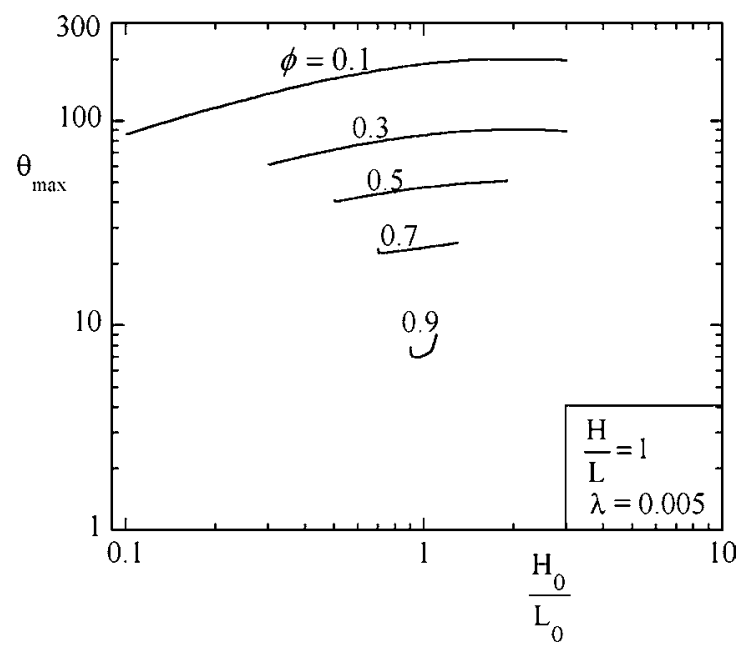

Figure 2: Minimization of the dimensionless global thermal resistance as function of $\mathrm{H}_{0} / \mathrm{L}_{0}$ for several values of the fraction of the area of the solid inserted into the cavity. 
minimizes the dimensionless global thermal resistance when the volume fraction $\phi_{0}$, the dimensionless group $\lambda$ and the degree of freedom $\mathrm{H} / \mathrm{L}$ are fixed. Figure 2 also shows the optimization of the dimensionless global thermal resistance, $\theta_{\max }$, for several values of the volume fraction of the solid inserted into the cavity, $\phi_{0}$.

The results of Fig. 2 were summarized in Fig. 3, which presents the once minimized dimensionless global thermal resistance, $\theta_{\text {max,m }}$, and the once optimized cavity ratio $\left(\mathrm{H}_{0} / \mathrm{L}_{0}\right)_{\mathrm{opt}}$, as function of the volume fraction, $\phi_{0}$. This figure indicates that $\theta_{\text {max,m }}$ decreases and $\left(\mathrm{H}_{0} / \mathrm{L}_{0}\right)_{\mathrm{opt}}$ increases when $\phi_{0}$ increases. The best shapes calculated in Fig. 3 are shown in Fig. 4. This figure confirms that cavities perform better when they penetrate almost completely into the body [12-14] when the ratio $\mathrm{H} / \mathrm{L}=1$.

Figure 5 shows the behavior of the dimensionless global thermal resistance, $\theta_{\max }$, as function of the dimensionless group $\lambda$ and the volume fraction $\phi_{0}$ when the cavity is square and the dimensionless group $\lambda$ is equal to 1 . This figure indicates that the dimensionless global thermal resistance decreases when the volume fraction $\phi_{0}$ and the dimensionless group $\lambda$ increase. The effect of the dimensionless group $\lambda$ and the volume fraction $\phi_{0}$ in the optimal shape of the $\mathrm{C}$-shaped cavity is shown in Fig. 6 . The optimal shape of the $\mathrm{C}$-cavity is almost insensitive when the volume fraction is small or large.

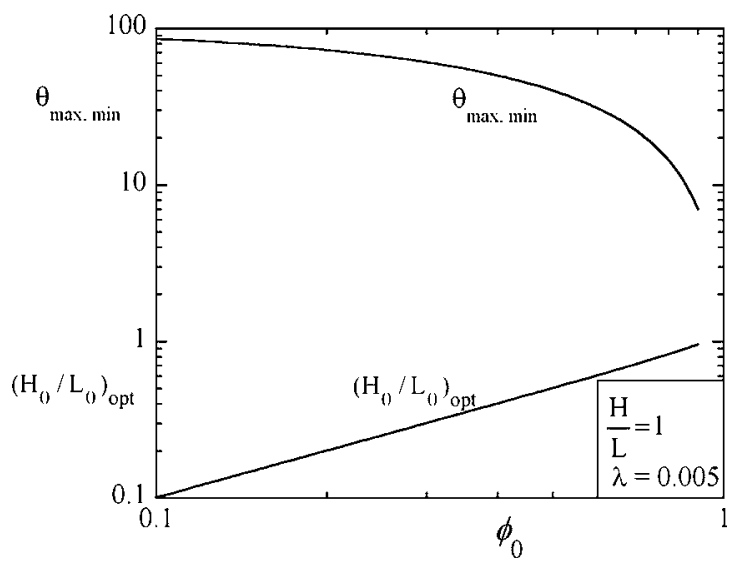

Figure 3: The behavior of the best shapes and the minimal dimensionless global thermal resistance calculated in Fig. 2 as function of the volume fraction $\phi_{0}$.

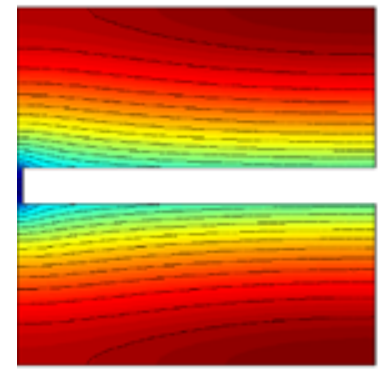

$\phi_{0}=0.1$

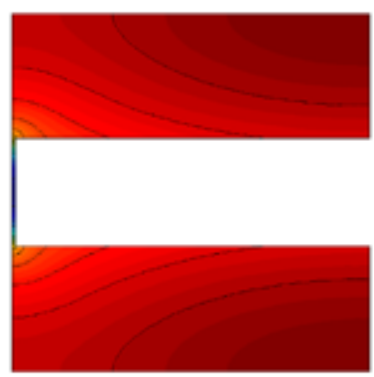

$\phi_{0}=0.3$

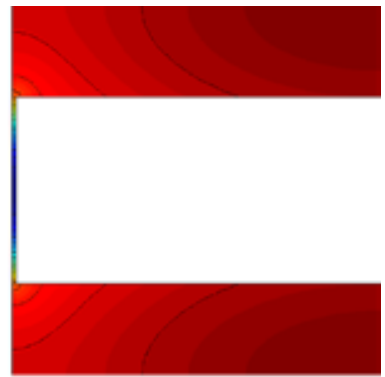

$\phi_{0}=0.5$

Figure 4: Illustration of some optimal shapes from Fig. 3. 


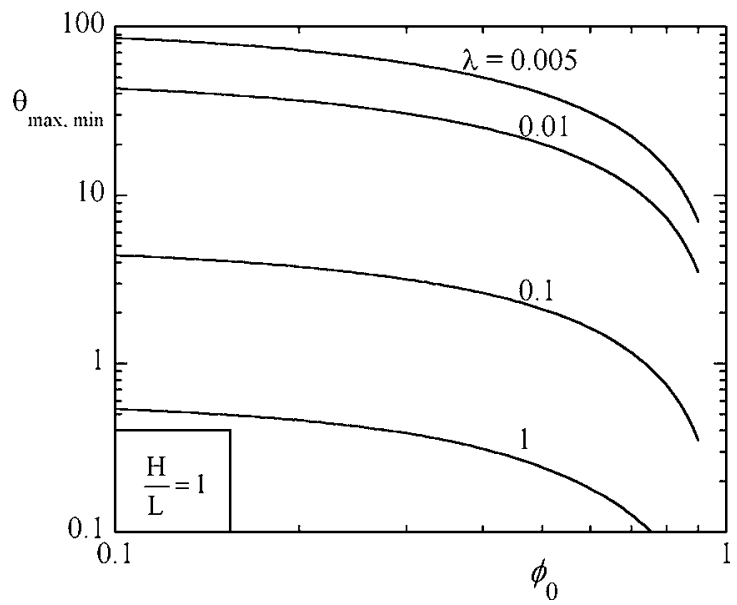

Figure 5: The behavior of the dimensionless global thermal resistance $\left(\theta_{\max }\right)$ as function of the dimensionless group $\lambda$ and the volume fraction $\phi_{0}$.

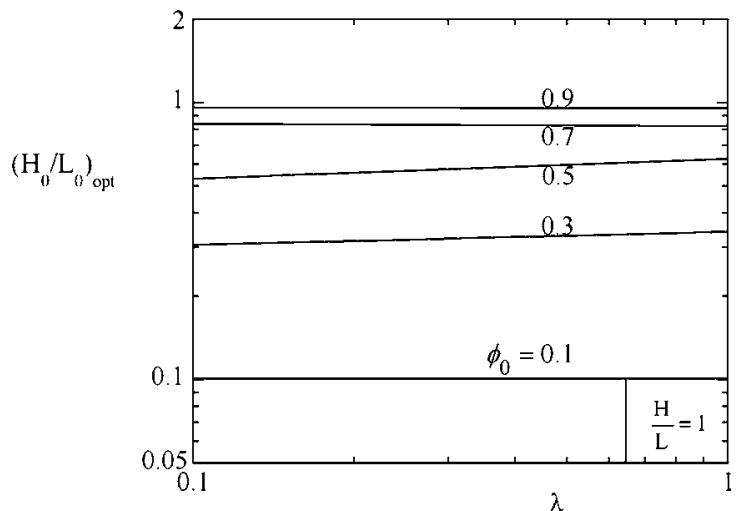

Figure 6: The effect of the dimensionless group $\lambda$ on the optimal shape of the C-shaped cavity for several values of volume fraction $\phi_{0}$.

However, this optimal shape increases when the dimensionless group $\lambda$ increases in the range $0.3 \leq$ $\phi_{0} \leq 0.7$, and this increment is maximal and approximately $20 \%$ when $\phi_{0}=0.5$ and $\lambda=1$.

Figure 7 presents a comparison between the optimal cavity ratio calculated for the isothermal C-shaped square cavity [12] and the cavity bathed by convection. The results show that the optimal shape of the cavities is almost the same for $\lambda \leq 0.01$. Both results also agree for $\phi_{0}<0.3$ and $\phi_{0}>0.7$. However, in the range $0.3 \leq \phi_{0} \leq 0.7$, the ratio $\left(\mathrm{H}_{0} / \mathrm{L}_{0}\right)_{\text {opt }}$ calculated for the cavities cooled by convection is greater than the optimal shape calculated for isothermal cavities. This difference is approximately $17 \%$ when $\lambda=0.1$ and $\phi_{0}=0.7$, and $20 \%$ for $\lambda=1$ and $\phi_{0}=0.5$.

The next step in the search for best shapes is to investigate the behavior of the dimensionless global thermal resistance by varying its external shape, H/L. We do this simulation by fixing the dimensionless group $\lambda$ equal to 0.005 and by repeating the procedure of Figs 2 and 3 for several values of H/L. Figure 8 shows that the dimensionless global thermal resistance presents a maximum 


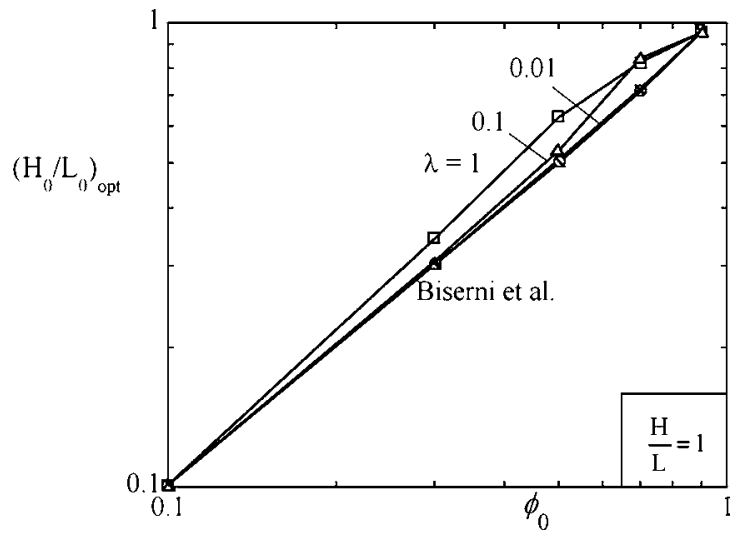

Figure 7: Comparison between the optimal ratio $\left(\mathrm{H}_{0} / \mathrm{L}_{0}\right)_{\text {opt }}$ obtained in this work with the ones calculated by Biserni et al. for isothermal square cavities.

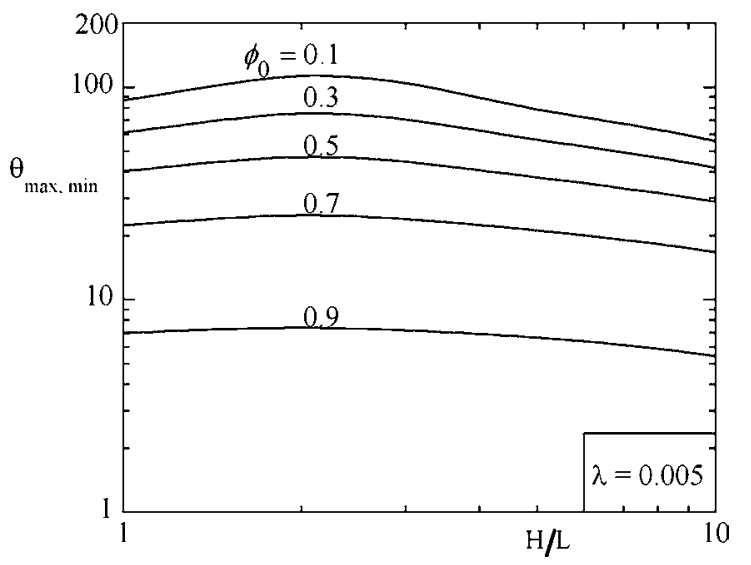

Figure 8: The behavior of the minimal dimensionless global thermal resistance as function of the ratio $\mathrm{H} / \mathrm{L}$ and the volume fraction $\phi_{0}$.

when $\mathrm{H} / \mathrm{L}=2$ and increases when $\phi_{0}$ increases. Therefore, cavities with small or large external ratios $\mathrm{H} / \mathrm{L}$ present better performance in the range of the studied external ratio. It is also interesting to notice in Fig. 9 that the optimal ratio $\left(\mathrm{H}_{0} / \mathrm{L}_{0}\right)_{\text {opt }}$ is unique except for the external ratio $\mathrm{H} / \mathrm{L}=2$. For this external ratio there are two $\left(\mathrm{H}_{0} / \mathrm{L}_{0}\right)_{\text {opt }}$ values for all the studied values of the volume fraction $\phi_{0}$, except for $\phi_{0}=0.9$, where there is a unique value for $\left(\mathrm{H}_{0} / \mathrm{L}_{0}\right)_{\mathrm{opt}}$. The optimal ratio $\left(\mathrm{H}_{0} / \mathrm{L}_{0}\right)_{\text {opt }}$ increases when the external ratio $\mathrm{H} / \mathrm{L}$ also increases. The effect of the volume fraction $\phi_{0}$ is also shown in Fig. 9. The optimal ratio $\left(\mathrm{H}_{0} / \mathrm{L}_{0}\right)_{\mathrm{opt}}$ increases when the volume fraction increases for values of the external ratio $\mathrm{H} / \mathrm{L}$ smaller than 2 . When the external ratio $\mathrm{H} / \mathrm{L}$ is greater than 2 the optimal ratio $\left(\mathrm{H}_{0} / \mathrm{L}_{0}\right)_{\mathrm{opt}}$ increases when the volume fraction $\phi_{0}$ decreases. Finally, some of the best configurations of Fig. 9 are presented in Fig. 10 for several values of the external ratio H/L. It is worthy to know that for values of $\mathrm{H} / \mathrm{L}$ greater than 2 the best shape is no longer the one that penetrates completely into the solid wall, but the one that presents the largest cavity aspect ratio $\mathrm{H}_{0} / \mathrm{L}_{0}$. 


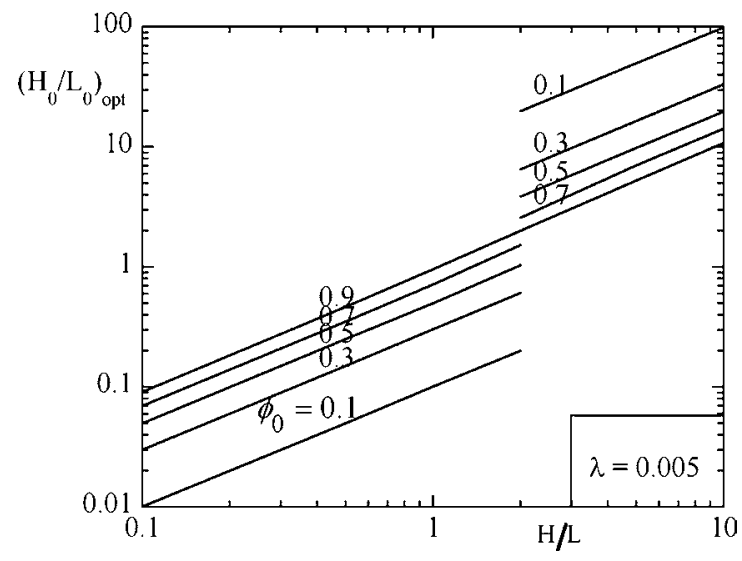

Figure 9: The behavior of the optimized ratio $\left(\mathrm{H}_{0} / \mathrm{L}_{0}\right)$ as function of the ratio $\mathrm{H} / \mathrm{L}$ and the volume fraction $\phi_{0}$.

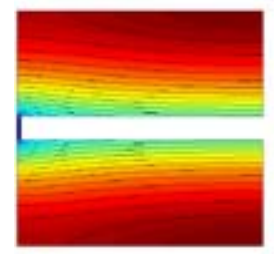

$\mathrm{H} / \mathrm{L}=1$

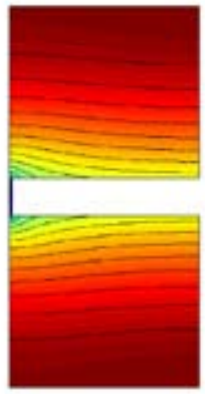

$\mathrm{H} / \mathrm{L}=2$

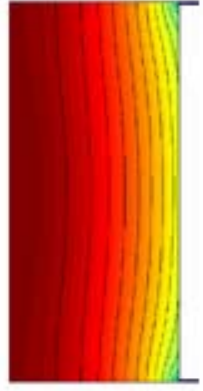

$\mathrm{H} / \mathrm{L}=2$

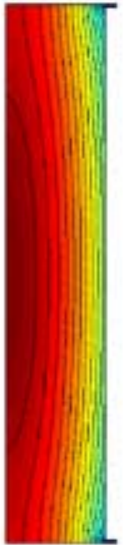

$H / L=s$

Figure 10: Examples of the best shapes calculated in Fig. 9 for the volume fraction $\phi_{0}=0.1$.

\section{CONCLUSIONS}

This work applies constructal design method to perform the minimization of the global thermal resistance of a C-shaped cavity inserted into a solid wall which generates volumetric heat uniformly. The cavity is cooled by convection heat transfer.

The results show that cavities cooled by convection heat transfer perform better if they penetrate almost completely into the body when the external ratio of the solid wall, H/L, is smaller than 2 .

The dimensionless global thermal resistance, $\theta_{\max }$, decreases when the volume fraction $\phi_{0}$ and the dimensionless group $\lambda$ increase. When compared with the optimal cavity ratio calculated for the isothermal C-shaped square cavity [12], the cavities cooled by convection have almost the same optimal shape for values of the dimensionless group $\lambda \leq 0.01$. Both cavities, isothermal and cooled by convection, also present similar optimal shapes for $\phi_{0}<0.3$ and $\phi_{0}>0.7$. However, in the range $0.3 \leq \phi_{0} \leq 0.7$ the ratio $\left(\mathrm{H}_{0} / \mathrm{L}_{0}\right)_{\text {opt }}$ calculated for the cavities cooled by convection is greater than the one presented by isothermal cavities. This difference is approximately $17 \%$ when $\lambda=0.1$ and $\phi_{0}=$ 0.7 , and $20 \%$ for $\lambda=1$ and $\phi_{0}=0.5$. This means that cavities with small or large external ratios $\mathrm{H} / \mathrm{L}$ 
present better performance. It is also interesting to notice that the optimal ratio $\left(\mathrm{H}_{0} / \mathrm{L}_{0}\right)_{\mathrm{opt}}$ is unique for each selected external ratio $\mathrm{H} / \mathrm{L}$, except for the external ratio $\mathrm{H} / \mathrm{L}=2$. For this external ratio there are two $\left(\mathrm{H}_{0} / \mathrm{L}_{0}\right)_{\text {opt }}$ values for all the studied values of the volume fraction $\phi_{0}$, except for $\phi_{0}=0.9$, when there is a unique value for $\left(\mathrm{H}_{0} / \mathrm{L}_{0}\right)_{\text {opt }}$. The optimal ratio $\left(\mathrm{H}_{0} / \mathrm{L}_{0}\right)_{\text {opt }}$ increases when the external ratio $\mathrm{H} / \mathrm{L}$ also increases. The optimal ratio $\left(\mathrm{H}_{0} / \mathrm{L}_{0}\right)_{\text {opt }}$ increases when the volume fraction increases for values of the external ratio $\mathrm{H} / \mathrm{L}$ smaller than 2 . When the external ratio $\mathrm{H} / \mathrm{L}$ is greater than 2 , the optimal ratio $\left(\mathrm{H}_{0} / \mathrm{L}_{0}\right)_{\text {opt }}$ increases when the volume fraction $\phi_{0}$ decreases.

It is worthy to know that for values of $\mathrm{H} / \mathrm{L}$ greater than 2 the best shape is no longer the one that penetrates completely into the solid wall, but the one that presents the largest cavity aspect ratio $\mathrm{H}_{0} / \mathrm{L}_{0}$.

\section{ACKNOWLEDGEMENTS}

Professor Giulio Lorenzini's work was sponsored by the Italian Ministry for Education, University and Research. Professor Cesare Biserni was funded by Italian MIUR. Professor Luiz Rocha's work was sponsored by CNPq, Brasília, DF, Brazil.

\section{REFERENCES}

[1] Bejan, A., Advanced Engineering Thermodynamics, 2nd edn, Willey, New York, 1997.

[2] Bejan, A., Shape and Structure, from Engineering to Nature, Cambridge University Press, Cambridge, UK: 2000.

[3] Bejan, A. \& Lorente, S., Design with Constructal Theory, Wiley: Hoboken, 2008. doi:10.1002/9780470432709

[4] Bejan, A. \& Lorente, S., Constructal theory of generation of configuration in nature and engineering. Journal of Applied Physics, 100, pp. 041301, 2006. doi:10.1063/1.2221896

[5] Kraus, A.D., Developments in the analysis of finned arrays, Donald Q. Kern Award Lecture, National Heat Transfer Conference, Baltimore, MD, August 11, 1997, International Journal of Transport Phenomena, 1, pp. 141-164, 1999.

[6] Aziz, A., Optimum dimensions of extended surfaces operating in a convective environment. Applied Mechanics Reviews, 45(5), pp. 155-173, 1992. doi:10.1115/1.3119754

[7] Falter, H.D. \& Thompson, E., Performance of hypervapotron beamstopping elements at jet. Fusion Technol, 29, pp. 584-594, 1996.

[8] Biserni, C. \& Lorenzini, G., Experimental tests on subcooled boiling heat transfer under forced convection conditions. J. Eng. Thermophys., 11, pp. 73-81, 2002.

[9] Lorenzini, G.C. \& Biserni, A., Vapotron effect application for electronic equipment cooling. J. Electron. Packaging, 125, pp. 475-479, 2003. doi:10.1115/1.1615796

[10] Lorenzini, G. \& Rocha, L.A.O., Constructal design of Y-shaped assembly of fins. Int. J. Heat Mass Transfer, 49, pp. 4552-4557, 2006. doi:10.1016/j.ijheatmasstransfer.2006.05.019

[11] Lorenzini, G. \& Rocha, L.A.O., Constructal design of T-Y assembly of fins for an optimal heat removal. Int. J. Heat Mass Transfer, 52, pp. 1458-1463, 2009. doi:10.1016/j. ijheatmasstransfer.2008.09.007

[12] Biserni, C., Rocha, L.A.O., \& Bejan, A., Inverted fins: geometric optimization of the intrusion into a conducting wall. Int. J. Heat Mass Transfer, 47, pp. 2577-2586, 2004. doi:10.1016/j. ijheatmasstransfer.2003.12.018

[13] Rocha, L.A.O., Lorenzini, E. \& Biserni, C., Geometric optimization of shapes on the basis of Bejan's Constructal theory. Int. Commun. Heat Mass Transfer, 32, pp. 1281-1288, 2005. doi:10.1016/j.icheatmasstransfer.2005.07.010

[14] Biserni, C., Rocha, L.A.O., Stanescu, G. \& Lorenzini, E., Constructal H-shaped cavities according to Bejan's theory. Int. J. Heat Mass Transfer, 50, pp. 2132-2138. 2007. doi:10.1016/j. ijheatmasstransfer.2006.11.006

[15] MATLAB, User's Guide, version 6.0.088, release 12, The Mathworks Inc., 2000. 